\title{
ANTIDEPRESSANT ACTIVITY OF THYMOQUINONE POSSIBLY THROUGH INVOLVEMENT OF CORTICOTROPIN-RELEASING FACTOR
}

\author{
HARSHITA JAIN ${ }^{1 *}$, PRATEEK JAIN ${ }^{2}$, BHARTI AHIRWAR ${ }^{3}$, DHEERAJ AHIRWAR ${ }^{1}$ \\ ${ }^{1}$ Department of Pharmacology, School of Pharmacy, Chouksey Engineering College, Bilaspur - 495 004, Chhattisgarh, India. ${ }^{2}$ Department of \\ Chemistry, ADINA Institute of Pharmaceutical Sciences, Sagar, Madhya Pradesh - 470 002, India. ${ }^{3}$ Department of Pharmacy, Guru Ghasidas \\ Central University, Bilaspur - 495 009, Chhattisgarh, India. Email: harshi.jain1987@gmail.com
}

Received: 02 August 2017, Revised and Accepted: 26 September 2017

ABSTRACT

Objective: Present study aimed to evaluate the antidepressant-like activity of thymoquinone (TQ) in unstressed and stressed condition and to explore the possible underlying mechanism for this activity.

Methods: TQ $(5,10$, and $20 \mathrm{mg} / \mathrm{kg}$ ) and fluoxetine per se were administered to the unstressed and stressed mice; immobility periods were observed using forced swim test (FST) and tail suspension test (TST). Effect of corticotropin-releasing factor (CRF)-1 antagonist on antidepressant-like activity was also evaluated. The mechanism of action was also explored by measuring plasma corticosterone levels.

Results: TQ (20 mg/kg) and fluoxetine per se significantly decreased immobility periods in stressed mice indicating significant antidepressant-like activity under stress. There was no significant effect on locomotor activity of the mice on treatment with TQ and fluoxetine per se. It significantly decreased plasma corticosterone level. Antalarmin (a CRF-1 receptor antagonist) significantly attenuated TQ induced the antidepressant-like effect in both FST and TST.

Conclusion: TQ significantly produced antidepressant-like activity in mice possi-bly through inhibiting CRF activity and decreasing plasma corticosterone levels.

Keywords: Immobilization, Thymoquinone, Corticotrophin-releasing factor

(c) 2017 The Authors. Published by Innovare Academic Sciences Pvt Ltd. This is an open access article under the CC BY license (http://creativecommons. org/licenses/by/4. 0/) DOI: http://dx.doi.org/10.22159/ajpcr.2017.v10i11.21773

\section{INTRODUCTION}

Depression is a mood disorder that affected more than 300 million people worldwide and is the most prevalent neuropsychiatric disorder. Investigations have demonstrated that depression encompasses a profound neurocircuitry failure. The brain regions involved in this dysregulation may include the hypothalamus, hippocampus, amygdala, and striatum $[1,2]$. These nuclei are important regulators in endocrine control of behaviors symptomatic of depression such as eating, sleeping, circadian rhythm, stress response, learning and memory, and pleasure seeking [3]. Depression is characterized by persistent sadness and a loss of interest in activities that people normally enjoy accompanied by an inability to carry out daily activities.

Depression and stress have a strong interlinking and have been well established. A key factor in response to stress is the neuropeptide corticotropin-releasing factor (CRF) [4]. CRF and its receptors (CRFR1 and CRFR2) are important regulators of the hypothalamic-pituitaryadrenal (HPA) axis. Evidence build up knot bridging CRF to the development of depression [5-9]. Clinical studies have found increased $\mathrm{CRF}$ and decreased CRF receptors in postmortem examination of suicide victims. In addition, excessive activation of the HPA axis has been reported in more than one-half of patients with depression, and these symptoms have been corrected during antidepressant treatment [7].

During a stress response, the hypothalamus is activated and releases CRF (also known as corticotropin-releasing hormone), which stimulates the release of adrenocorticotropic hormone (ACTH) from the pituitary gland. ACTH induces glucocorticoid synthesis and releases from the adrenal/interrenal tissue into the blood [10].
This stress-related neuropeptide acts at the level of the pituitary to initiate the HPA axis response stress [4-12]. CRF containing neurons are not confined to hypothalamic regions; they are also found in a number of neural circuits that mediate information processing and behavior. CRF has been shown to modulate diverse neurotransmitter systems including glutamate, dopamine, serotonin, and norepinephrine [13-15]. Modulation of serotonin and norepinephrine release by CRF supports its effective role in depression $[16,17]$.

Thymoquinone (TQ) is the most abundant component of seed oil of Nigella sativa. It possesses pharmacological activities including analgesic and anti-inflammatory activity [18], protection against chemical-induced carcinogenesis [19], inhibition of eicosanoids generation, and membrane lipid peroxidation [20]. The effects of TQ on central nervous system include neuroprotection [21], suppression of epilepsy [22], attenuation of nociceptive response [18], and suppression of oxidative stress-induced neuropathy [23]. At the molecular level, TQ has been shown to downregulate tumor necrosis factor [24] and suppress nuclear factor-kappa B activation in the brain and spinal cord $[25,26]$. TQ significantly reduced protein levels of inducible nitric oxide synthase (iNOS) and inhibited an increase in iNOS mRNA [23]. Further, TQ has served to enhance the survival of pancreatic beta cells by nitric oxide inhibitory mechanism [27]. Further TQ the major constituent of $N$. sativa seeds, administered by oral route, and intracerebroventricular injection exerts anticonvulsant activity that is reversed by flumazenil $[22,28]$.

Literature search showed us that there had been no study investigating the effect of TQ on depression. This study was aimed to investigate the effects of TQ in mice subjected to forced swim test (FST) and tail suspension test (TST) and to compare its effects with a conventional 
SSRI fluoxetine. For determining the effects of the immobilization (IM) session and drug therapy, duration of immobility of the animals was recorded. At the end of the IM session, TST and FST, which are known to be the frequently used and effective methods to evaluate depression, were applied to all of the animals to assess the ability of drugs to reverse stress-induced effects. This study was designed to investigate the potential of $\mathrm{TQ}$ as an antidepressant under stress and explore the involvement of CRF in mediating its effect.

\section{METHODS}

Swiss albino mice (20-25 g) were employed in the study. Animals were procured from the DRDE, Gwalior, India. Animals were housed separately in groups of $10 /$ cage under laboratory conditions with alternating light and dark cycles of $12 \mathrm{hrs}$ each. They had free access to food and water. The animals were acclimatized to the laboratory conditions before behavioral experiments. Animals were kept fasted $2 \mathrm{hrs}$ before $2 \mathrm{hrs}$ before drug administration. The animals were acclimatized for 5 days before behavioral experiments which were carried between 8:00 and 17:00 hrs. The experimental protocol was approved by the Institutional Animal Ethics Committee, and care of the animals was taken as per the guidelines of the Committee for the Purpose of Control and Supervision of Experiments on Animals.

\section{Drugs}

The following drugs and chemicals were used in this study: Fluoxetine hydrochloride, p-nitroso-N, N-dimethylaniline, TQ, antalarmin (AA) hydrochloride (Sigma-Aldrich, St. Louis, USA), boric acid, hydrochloric acid, and potassium hydroxide (CDH Ltd., New Delhi).

\section{Laboratory models employed for evaluation of antidepressant activity \\ TST}

It is a commonly employed behaviors test to evaluate antidepressantlike activity. The test was performed according to the method described by Steru et al. [29] for evaluating potential antidepressants. The total duration of immobility induced by tail suspension was measured according to the method described. Mice were suspended on the edge of a table $50 \mathrm{~cm}$ above the floor with the help of a paper adhesive tape placed approximately $1 \mathrm{~cm}$ from the tip of the tip of the tail. Immobility time was recorded for 6 min period. The mice were considered to be immobile only when they hung passively and were completely motionless [30].

\section{FST}

It is another seldom used behavioral test to evaluate antidepressantlike activity. FST was proposed as a model to test antidepressant activity by Porsolt et al., mice were forced to swim individually in glass jar $(25 \times$ $15 \times 25 \mathrm{~cm}^{3}$ ) containing fresh water up to $15 \mathrm{~cm}$ height and maintained at $25 \pm 3^{\circ} \mathrm{C}$. After an initial 2 minutes period of vigorous activity, each animal assumed a typical immobile posture. Mice were considered to be immobile when it remained floating in the water without struggling, making only minimum movements of its limbs, necessary to keep its head above the water. The total duration of immobility was recorded during the last 4 minutes of the total test duration of 6 minutes. The changes in immobility duration were studied after administrating the drugs in separate groups of animals [31]. Each animal was used only once in this test.

\section{Locomotor activity test}

The effect of various treatments on locomotor activity was observed in actophotometer (Inco, Ambala, India). The locomotor activity scores for each animal were recorded for 10 minutes [32].

\section{Biochemical estimations}

CRF

Measurement of CRF levels was performed by enzyme immunoassay or ELISA using commercially available kit: Mouse/Rat CRF-HS ELISA kit (ALPCO Diagnostics). For determination, the brains were rapidly removed from mice after completing behavioral tests and isolated brain were weighed and homogenized in 30-fold volume of extraction buffer $10 \mathrm{mM}$ phosphate-buffered saline $(\mathrm{pH} 7.2)$ containing $0.2 \%$ Nonidet $\mathrm{P}-40$ in an ice bath. It was centrifuged $(18360 \times \mathrm{g}, 20$ minutes $)$ and the supernatant was collected and used for measurement. The procedure followed was as described earlier [33,34].

\section{Plasma corticosterone estimation}

For corticosterone estimation, blood was withdrawn from tail vein of mice immediately before setting the animal free and subjecting it to behavioral tests in all the groups. The sampling procedure was completed during IM to avoid the extra stress incurred on mice during an altogether a new procedure of mouse IM for handling the tail of mice. Plasma was separated using cooling centrifuge at 2500 r.p.m. (Remi Centrifuge, Mumbai, India) for $10 \mathrm{~min}$. Corticosterone levels were estimated in blood plasma by Bartos and Pesez method [35]. To $1.0 \mathrm{ml}$ of plasma sample, $1.0 \mathrm{ml}$ of ethanol, and $0.50 \mathrm{ml}$ of $0.10 \%$ solution of p-nitroso- $\mathrm{N}, \mathrm{N}$-dimethylaniline in ethanol were added, and the tubes were immersed in ice water for 5 minutes, and then, $0.50 \mathrm{ml}$ of $0.1 \mathrm{~N}$ sodium hydroxide was added. The tubes were plugged with cotton-wool, and let to stand at $0^{\circ} \mathrm{C}$ for $5 \mathrm{hrs}$, protected from light. To the above solution, $2.0 \mathrm{ml}$ of Clark and Lubs buffer for pH 9.8 (prepared by mixing $50.0 \mathrm{ml}$ of an aqueous solution of both boric acid and potassium chloride with $40.8 \mathrm{ml}$ of $0.20 \mathrm{M}$ potassium hydroxide, and diluted to $200 \mathrm{ml}$ with distilled water), $5.0 \mathrm{ml}$ of $0.10 \%$ solution of phenol in ethanol, and $0.50 \mathrm{ml}$ of $1.0 \%$ aqueous solution of potassium ferricyanide were added. The tubes were kept in water bath at $20 \pm 2^{\circ} \mathrm{C}$ for 10 minutes. The absorbance of the solution was read at $650 \mathrm{~nm}$ using ultraviolet spectrophotometer (Shimadzu-1800).

\section{Experimental design}

Sixteen groups of mice were employed in the study. Each group consisted of minimum eight mice. Stress was produced in them by immobilizing for 6 hrs ( 8 a.m. - 2 p.m.) by taping all its four limbs and trunk on a wooden board [32]. Mice subjected to IM were called as stressed mice, and mice not subjected to IM were called as unstressed mice and have been mentioned accordingly. Behavioral testing was performed carefully in a stepwise manner, i.e. ,mice in each group were subjected to three tests [36]: (a) TST, then, a 6 minutes rest in home cage, thereafter, (b) locomotor activity test in actophotometer, again followed by 6 minutes rest, and then, (c) FST. All the drugs were administered intraperitoneally (i.p.) 30 minutes before the behavioral testing in unstressed group and immediately before IM in stressed group. When combinations of the drugs were employed, pretreatments were administered 15 minutes before the administration of the other drug. For CRF determination, the brain was rapidly removed from mice after behavioral tests.

\section{Statistical analysis}

All the results were expressed as mean \pm standard error mean. The data were analyzed using 1-way ANOVA followed by Tukey's test for multiple comparisons using the software GraphPad InStat. In all tests, the criterion for statistical significance was $\mathrm{p}<0.05$.

\section{RESULTS}

Study showed that IM stress has marked effect on depression and TQ decreased immobility time in stressed condition at $20 \mathrm{mg} / \mathrm{kg}$, but in unstressed condition, TQ has no significant effect on immobility time. This indicated significant antidepressant effect of TQ under stress.

Different treatments provided to stressed group showed different effects. AA (10 mg/kg i.p.) administered alone to stressed group, significantly decreased immobility time in TST as well FST (Fig. 1). unstressed group didn't significantly decrease immobility time in both behavioural paradigms. A significant decrease in immobility 
time was observed when AA (10 mg/kg) was administered in combination with TQ $(10 \mathrm{mg} / \mathrm{kg})$ in the stressed group as compared to TQ $(10 \mathrm{mg} / \mathrm{kg})$ group. Similarly, when AA $(10 \mathrm{mg} / \mathrm{kg})$ and TQ $(20 \mathrm{mg} / \mathrm{kg})$ were administered together a significant decrease in immobility time was observed in both TST as well as FST. As shown in Fig. 2, locomotor activities were not affected by treatment with TQ alone, but AA increased it, and its combination with TQ $(10,20 \mathrm{mg} / \mathrm{kg})$ again restored the counts.

Treatments on the unstressed group did not significantly change levels of CRF. As shown in Fig. 3, co-administration of AA $(10 \mathrm{mg} /$ $\mathrm{kg})$ and $\mathrm{TQ}(10,20 \mathrm{mg} / \mathrm{kg})$ did not have any significant changes in brain levels of CRF as compared to AA (10 mg/kg) alone. Whereas a significant decrease in corticosterone levels was found in the group treated with AA (10 mg/kg) administered along with TQ $10 \mathrm{mg} / \mathrm{kg}$ as well as $20 \mathrm{mg} / \mathrm{kg}$ as compared to their respective TQ-treated group (Table 1).

\section{DISCUSSION}

In the present study, TQ $(20 \mathrm{mg} / \mathrm{kg})$ administered to mice under stressed condition produced significant antidepressant-like activity in TST and FST. This is the first study showing on antidepressant effect of $\mathrm{TQ}$ on IM stress for $6 \mathrm{hrs}$. The efficacy of TQ was found to be comparable with fluoxetine. FST and TST are two commonly used behavioral despair models of depression. These models are widely employed in rodents to evaluate antidepressant potential through decreasing immobility
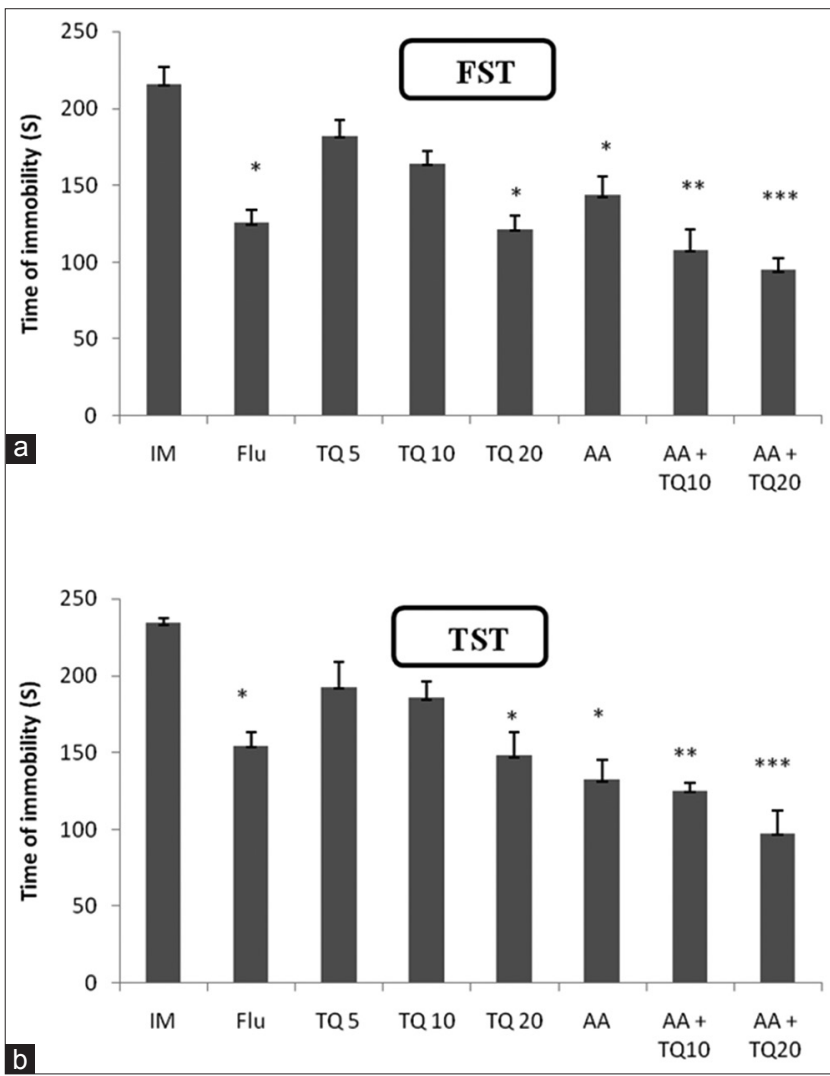

Fig. 1: (a and b) Effect of different treatments on immobility time on stressed mice in forced swim test (FST) as well as tail suspension test (TST), $n=8$ in each group. Values are expressed as mean \pm standard error. Data were analyzed by one-way ANOVA followed by Turkey's post hoc test, in FST F $(7,40)=57.06$ TST $F(7,40)=90.46 ; p<0.0001,{ }^{*} p<0.001$ significant difference from immobilized group, $* * \mathbf{p}<0.05$ significant difference from $\mathrm{TQ}$ $(10 \mathrm{mg} / \mathrm{kg})$-treated group, ${ }^{* * *} \mathrm{p}<0.05$ significant difference from TQ (20 mg/kg)-treated group, IM: Immobilization, TQ: Thymoquinone, and AA: Antalarmin. Doses mentioned are in $\mathrm{mg} / \mathrm{kg}$ period produced by different classes of antidepressant drugs [29,37]. TQ did not show any effect on locomotor activity as compared to the vehicle-treated group in unstressed condition as well as an immobilized group in stressed condition.

In FST, mice are forced to swim in constrained area which restricts their escape that attributes immobility in them. This behavior reflects a state of despair which can be reduced by several agents which are therapeutically effective in human depression. The TST also induces a state of immobility in animals like that in FST. This immobility referred as behavioral despair in animals, which is claimed to

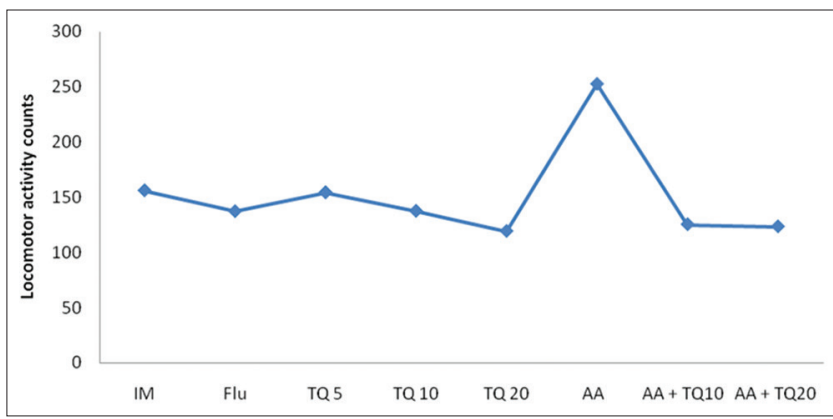

Fig. 2: The effect of different treatments on locomotor activity in stressed mice expressed in locomotor activity counts. $n=8$ in each group. IM: Immobilization, FLU: Fluoxetine, TQ: Thymoquinone, and AA: Antalarmin. Doses mentioned are in $\mathrm{mg} / \mathrm{kg}$

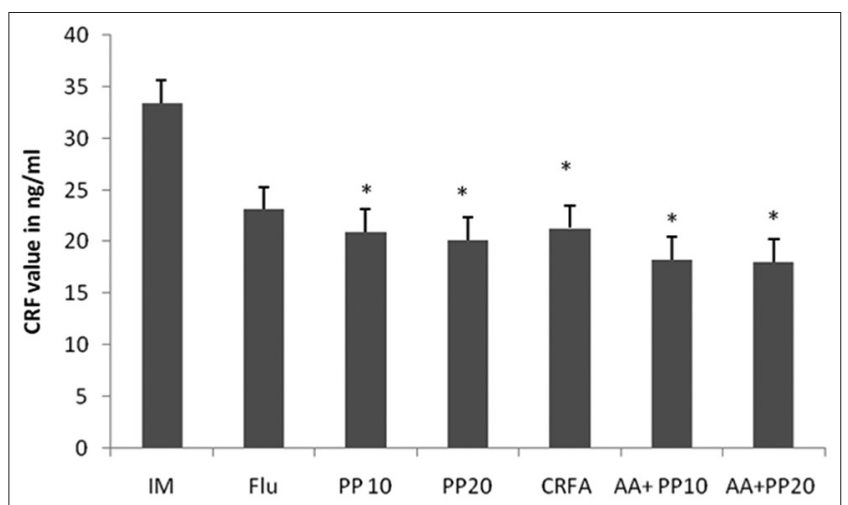

Fig. 3: Effect of different treatments on corticotropin-releasing factor level $(\mathrm{ng} / \mathrm{ml})$ in stressed mice. $\mathrm{n}=8$ in each group. Values are expressed as mean \pm standard error. Data were analyzed by one-way ANOVA followed by Tukey's post hoc test, $F(7,40)=5.2$; $\mathrm{p}<0.0001,{ }^{*} \mathbf{p}<0.01$ significant difference from the immobilized group. IM: Immobilization, FLU: Fluoxetine, TQ: Thymoquinone, and AA: Antalarmin. Doses mentioned are in $\mathrm{mg} / \mathrm{kg}$

Table 1: Effect of treatments on corticosterone levels

\begin{tabular}{lll}
\hline Group & Treatment & Concentration in pg/ml \\
\hline Group I & Immo & 621.2 \\
Group IV & TQ 10 & $483.5^{*}$ \\
Group V & TQ 20 & $438.3^{*}$ \\
Group VI & AA S & $381.0^{*}$ \\
Group VII & AA + TQ 1 & $86.9^{* *}$ \\
Group VIII & AA + TQ 2 & $84.9^{* * *}$ \\
\hline
\end{tabular}

Effect of different treatments on plasma corticosterone levels. Values are expressed as mean \pm standard error. Data were analyzed by one-way ANOVA followed by Tukey's post hoc test. $\mathrm{F}(7,40)=40.90, \mathrm{p}<0.0001,{ }^{*} \mathrm{p}<0.001$ significant difference from immobilized group, ${ }^{* *} \mathrm{p}<0.001$ significant difference from TQ $10 \mathrm{mg} / \mathrm{kg}$-treated group, ${ }^{* * *} \mathrm{p}<0.001$ significant difference from TQ $20 \mathrm{mg} / \mathrm{kg}$ treated group. IM: Immobilization, FLU: Fluoxetine, TQ: Thymoquinone, AA: Antalarmin. Doses mentioned are in $\mathrm{mg} / \mathrm{kg}$ 
reproduce a condition similar to human depression [29,38,39]. Out of three doses of TQ, $20 \mathrm{mg} / \mathrm{kg}$ PO produced a most significant effect in stressed mice whereas none of the dose of TQ produced a significant antidepressant effect in unstressed condition. The most effective dose of TQ was therefore employed in further study elucidating the mechanism of antidepressant-like activity. Treatment with antalarmin a CRF antagonist specifically antagonizing CRF-1 receptor reversed extended immobility time under stress in both FST and TST. TQ and antalarmin coadministered together made the belief stronger by declining immobility time and exerting a direct effect on plasma corticosterone. The most astonishing part was that brain CRF level remained untouched apart from these rapid combinations. Synergizing effect of TQ and antalarmin suggested that TQ may exert its effect by cooperating its coadministered drug and antagonizing CRF receptors.

Major depression has been linked with hyperactivity of the HPA axis [40]. High concentrations of blood glucocorticoid are maintained in patients with depression due to the dysfunction of this feedback mechanism [41]. High glucocorticoid levels cause pathological damage to the hippocampal neurons both in vitro and in vivo [42,43] and can induce depression-like behavior in animals [41,43]. Our results demonstrated TQ significantly reduced the plasma corticosterone levels, by directly acting on CRF receptors. Hence, the antidepressantlike action shown by the TQ may be due to inhibition of corticosterone production and CRF antagonism.

\section{CONCLUSION}

Our present study shows that TQ showed significant antidepressantlike activity in stressed mice probably by interaction with CRF-1 receptor as it reduced plasma corticosterone levels. Therefore, TQ can be explored further for its potential to treat clinical depression.

\section{REFERENCES}

1. Liotti M, Mayberg HS. The role of functional neuroimaging in the neuropsychology of depression. J Clin Exp Neuropsychol 2001;23(1):121-36.

2. Nestler EJ, Barrot M, DiLeone RJ, Eisch AJ, Gold SJ, Monteggia LM. Neurobiology of depression. Neuron 2002;34(1):13-25.

3. Bale TL, Vale WW. Increased depression-like behaviors in corticotrophin releasing factor receptor-2-deficient mice: Sexually dichotomous responses. J Neurosci 2003;23(12):5295-301.

4. Vale W, Spiess J, Rivier C, Rivier J. Characterization of a 41-residue ovine hypothalamic peptide that stimulates secretion of corticotrophin and beta-endorphin. Science 1981;213(4514):1394-7.

5. Nemeroff CB. The role of corticotropin-releasing factor in the pathogenesis of major depression. Pharmacopsychiatry 1988;21(2):76-82.

6. Nemeroff CB. New vistas in neuropeptide research in neuropsychiatry: Focus on corticotropin-releasing factor. Neuropsychopharmacology 1992;6(2):69-75.

7. Holsboer $F$. The rationale for corticotropin-releasing hormone receptor (CRH-R) antagonists to treat depression and anxiety. J Psychiatr Res 1999;33(3):181-214

8. Reul JM, Holsboer F. Corticotropin-releasing factor receptors 1 and 2 in anxiety and depression. Curr Opin Pharmacol 2002;2(1):23-33.

9. Arborelius L, Owens MJ, Plotsky PM, Nemeroff CB. The role of corticotropin-releasing factor in depression and anxiety disorders. J Endocrinol 1999;160(1):1-12.

10. Carrasco GA, Van de Kar LD. Neuroendocrine pharmacology of stress. Eur J Pharmacol 2003;463(1-3):235-72.

11. Bale TL, Vale WW. CRF and CRF receptors: Role in stress responsivity and other behaviors. Annu Rev Pharmacol Toxicol 2004;44:525-57.

12. Owens MJ, Nemeroff CB. Physiology and pharmacology of corticotropin-releasing factor. Pharmacol Rev 1991;43(4):425-73.

13. Lavicky J, Dunn AJ. Corticotropin-releasing factor stimulates catecholamine release in hypothalamus and prefrontal cortex in freely moving rats as assessed by microdialysis. J Neurochem 1993;60(2):602-12.

14. Price ML, Lucki I. Regulation of serotonin release in the lateral septum and striatum by corticotropin-releasing factor. J Neurosci 2001;21(8):2833-41.
15. Valentino RJ, Commons KG. Peptides that fine-tune the serotonin system. Neuropeptides 2005;39(1):1-8.

16. Charney DS. Psychobiological mechanisms of resilience and vulnerability: Implications for successful adaptation to extreme stress. Am J Psychiatry 2004;161(2):195-216.

17. Borah A, Singha B, Phukan S. Anti-depressant effect of ceftriaxone in forced swimming test and in tail suspension test in mice. Int J Pharm Pharm Sci 2016;8(11):191-4.

18. Abdel-Fattah AM, Matsumoto K, Watanabe H. Antinociceptive effects of Nigella sativa oil and its major component, thymoquinone, in mice. Eur J Pharmacol 2000;400(1):89-97.

19. Hassan M, El-Dakhakhny AM. Effect of some Nigela sativa constituents on chemical carcinogenesis in hamster cheek pouch. J Egypt Soc Pharmacol Exp Ther 1992;11:675-7.

20. Houghton PJ, Zarka R, de las Heras B, Hoult JR. Fixed oil of Nigella sativa and derived thymoquinone inhibit eicosanoid generation in leukocytes and membrane lipid peroxidation. Planta Med 1995;61(1):33-6.

21. Al-Majed AA, Al-Omar FA, Nagi MN. Neuroprotective effects of thymoquinone against transient forebrain ischemia in the rat hippocampus. Eur J Pharmacol 2006;543(1-3):40-7.

22. Hosseinzadeh H, Parvardeh S, Nassiri-Asl M, Mansouri MT. Intracerebroventricular administration of thymoquinone, the major constituent of Nigella sativa seeds, suppresses epileptic seizures in rats. Med Sci Monit 2005;11(4):BR106-10.

23. Hamdy NM, Taha RA. Effects of Nigella sativa oil and thymoquinone on oxidative stress and neuropathy in streptozotocin-induced diabetic rats. Pharmacology 2009;84(3):127-34.

24. El-Mahmoudy A, Matsuyama H, Borgan MA, Shimizu Y, El-Sayed MG, Minamoto N, et al. Thymoquinone suppresses expression of inducible nitric oxide synthase in rat macrophages. Int Immunopharmacol 2002;2(11):1603-11.

25. Mohamed A, Afridi DM, Garani O, Tucci M. Thymoquinone inhibits the activation of NF-kappaB in the brain and spinal cord of experimental autoimmune encephalomyelitis. Biomed Sci Instrum 2005; 41:388-93.

26. Sethi G, Ahn KS, Aggarwal BB. Targeting nuclear factor-kappa $B$ activation pathway by thymoquinone: Role in suppression of antiapoptotic gene products and enhancement of apoptosis. Mol Cancer Res 2008;6(6):1059-70.

27. El-Mahmoudy A, Shimizu Y, Shiina T, Matsuyama H, Nikami H, Takewaki T. Macrophage-derived cytokine and nitric oxide profiles in Type I and Type II diabetes mellitus: Effect of thymoquinone. Acta Diabetol 2005;42(1):23-30

28. Hosseinzadeh H, Parvardeh S. Anticonvulsant effects of thymoquinone, the major constituent of Nigella sativa seeds, in mice. Phytomedicine 2004:11(1):56-64.

29. Steru L, Chermat R, Thierry B, Simon P. The tail suspension test: A new method for screening antidepressants in mice. Psychopharmacology (Berl) 1985;85(3):367-70.

30. Dhingra D, Kumar V. Evidences for the involvement of monoaminergic and GABAergic systems in antidepressant-like activity of garlic extract in mice. Indian J Pharmacol 2008;40(4):175-9.

31. Dattatray BP, Padmaja AM, Nirmala NR. Antidepressant activity of aqueous extracts of fruits of terminalia chebula and phyllanthus emblica in behavioral models of depression: Involvement of monoaminergic system. Int J Pharm Pharm Sci 2014;6(8):615-20.

32. Gilhotra N, Dhingra D. Involvement of NO-cGMP pathway in anti-anxiety effect of aminoguanidine in stressed mice. Prog Neuropsychopharmacol Biol Psychiatry 2009;33(8):1502-7.

33. Nakane T, Audhya T, Hollander CS, Schlesinger DH, Kardos P, Brown C, et al. Corticotrophin-releasing factor in extra-hypothalamic brain of the mouse: Demonstration by immunoassay and immunoneutralization of bioassayable activity. J Endocrinol 1986;111(1):143-9.

34. Delawary M, Tezuka T, Kiyama Y, Yokoyama K, Inoue T, Hattori S, et al. NMDAR2B tyrosine phosphorylation regulates anxietylike behavior and CRF expression in the amygdala. Mol Brain 2010;3:37.

35. Bartos J, Pesez M. Colorimetric and fluorimetric determination of steroids. Pure Appl Chem 1979;51(10):2157-9.

36. Dunn AJ, Swiergiel AH. Effects of interleukin-1 and endotoxin in the forced swim and tail suspension tests in mice. Pharmacol Biochem Behav 2005;81(3):688-93.

37. Porsolt RD, Bertin A, Jalfre M. Behavioral despair in mice: A primary screening test for antidepressants. Arch Int Pharmacodyn Ther 1977;229(2):327-36

38. Thierry B, Stéru L, Simon P, Porsolt RD. The tail suspension test: 
Ethical considerations. Psychopharmacology (Berl) 1986;90(2):284-5

39. Willner P. The validity of animal models of depression. Psychopharmacology (Berl) 1984;83(1):1-16

40. Barden N. Implication of the hypothalamic-pituitary-adrenal axis in the physiopathology of depression. J Psychiatry Neurosci 2004;29:185-93

41. Johnson SA, Fournier NM, Kalynchuk LE. Effect of different doses of corticosterone on depression-like behavior and HPA axis responses to a novel stressor. Behav Brain Res 2006;168(2):280-8

42. Li S, Wang C, Wang M, Li W, Matsumoto K, Tang Y. Antidepressant like effects of piperine in chronic mild stress treated mice and its possible mechanisms. Life Sci 2007;80(15):1373-81.

43. Murray F, Smith DW, Hutson PH. Chronic low dose corticosterone exposure decreased hippocampal cell proliferation, volume and induced anxiety and depression like behaviours in mice. Eur J Pharmacol 2008;583(1):115-27. 